\title{
Literal Force: a Defence of Conventional Assertion ${ }^{1}$
}

\begin{abstract}
"But literal meaning may not (and in my view does not) go beyond truth conditions." Donald Davidson, "Communication and Convention", p. 269.

"Our difficulty arises from the fact that we have tried to characterize the activity of assertion without taking into account its being a conventional activity: the fact that a sentence expresses an act of assertion is as much a matter of linguistic convention as is its having the sense it has." Michael Dummett, Frege: Philosophy of Language, p. 300 .
\end{abstract}

The aim of this paper is to motivate and defend a conventional approach to assertion and other illocutionary acts. ${ }^{2}$ Such an approach takes assertions, questions and orders to be moves within an essentially rule-governed activity similar to a game. The most controversial aspect of a conventional account of assertion is that according to it, for classifying an utterance as an assertion, question or command, "it is irrelevant what intentions the person speaking may have had" (Dummett 1973, p. 302). I understand this to mean that it is irrelevant for the issue of whether an utterance is an assertion whether the utterer has certain communicative intentions, such as the intention to utter something true, the intention to get one's audience to believe (that one believes) what one has asserted etc. Just as one can commit a foul in football without meaning to do so, one can make an assertion, issue a command or ask a question without meaning to do so. The rules of football specify that a certain form of conduct (tackling an opponent in a certain way), carried out under certain general conditions (being a member of a team engaged in a game of football) counts as committing a foul. Similarly, I claim, the rules of language specify that a certain form of conduct (uttering an assertoric sentence), carried out under certain general conditions (being a member of a speech community engaged in a conversation) counts as making an assertion.

It is not part of the conventional approach defended here that there cannot also be a useful notion of assertion that is defined in terms of some suitable cocktail of communicative speaker intentions. On the contrary, a conventional account of assertion

\footnotetext{
${ }^{1}$ I would like to thank Manuel García-Carpintero, Rob Stainton and Peter Pagin for discussion and comments.

2 One version of such an approach was defended by Dummett (1973) and criticised by Davidson (1979, 1982) and Stainton (1995). More recently, Alston (2000) has revived this kind of view of assertion. Barker's (2004) notion of Proto-assertion is another recent, but more distant, descendant. However, the account I advocate differs from Dummett's in the treatment of fictional assertion, from that of Alston in that I do not oppose simultaneously using an intentional notion of assertion, and finally it differs from Barker's in that it does not constitute as radical a departure from standard semantics as his. My account can be seen as complementing Segal's (1990) and García-Carpintero's (2004) view that force-indicators should be treated within semantics, and García-Carpintero's $(2001,2004)$ "Neo-Gricean" view that languages are systems of conventional rules which we exploit for our communicative purposes.
} 
and other illocutionary acts is complemented by a pragmatic theory of the communicative intentions and actions of speakers. For this reason, I will distinguish conventional notions of C-assertion from notions of I-assertion: assertion defined in terms of the subject's communicative intentions. What is defended here is not an analysis of any pretheoretical notion of assertion. Rather, I am defending the claim that $\mathrm{C}$-assertion, C-question etc have an important and coherent role to play in a theory of linguistic communication.

The purpose of a conventional account of assertion is perhaps best explained by viewing it as the proposal that there is literal force in addition to literal content and literal subcontent. Most philosophers of language make a distinction between the literal, encoded meaning of utterance types, and the non-literal meaning which tokens (or tokenings) of those types can have on particular occasions of use. ${ }^{3}$ Without the notion of literal meaning, we would presumably be forced to deny the existence of contextinvariant meanings altogether. However, most philosophers of language employ such a distinction only at the level of the content, or subcontent, of utterances, not at the level of illocutionary force or speech acts. Most theorists have no room for a notion of literal assertion, i.e. a performance that counts as an assertion in virtue of the linguistic meaning of the utterance type used. Instead, these theorists employ a notion of assertion according to which asserting is a matter of having certain communicative intentions, with the result that they see themselves forced to deny the existence of illocutionary force indicators, i.e. context-invariant meaning at the level of speech acts. In this paper, I want to provide some motivation for admitting a notion of literal assertion and distinguishing this from assertion conceived of in terms of speaker intentions. The second aim is to dispose of some objections that have been made against this type of theory, namely Davidson's and Stainton's objections against Dummett's conception of assertion as a conventional act.

Sections 1-3 are introductory. I begin in $\S 1$ with some general considerations about essentially rule-governed action. In $\S 2$ I give a general characterization of conventional accounts of assertion. In $\S 3$, I provide a general characterization of intentional accounts of assertion. Sections 4-6 provide various motivations for employing a conventional notion of assertion and other speech acts. In $\S 4$ I explain the role a conventional notion of assertion can play in dealing with indirect speech acts. In $\$ 5$ I argue that the usual reasons for distinguishing between literal and non-literal meaning concern the force as much as the content of utterances. In $\S 6$ I show how the notion of conventional force helps avoid the sorts of problems Grice and Lewis have in grounding linguistic meaning in language use (or characterizing the actual-language relation). In §7 I deal with Davidson's objection against conventional force indicators, namely his argument from "non-serious" uses, such as in jokes or fictional utterances. In section 8 I finally tackle Stainton's alleged counterexamples to Dummett's conventional account of assertion, namely nonsentential assertions.

\footnotetext{
${ }^{3}$ There is a controversy about where exactly to draw the line between the literal and the non-literal, and there are debates about the relative location of the dividing line between what is said and what is otherwise conveyed. However, most participants of these debates accept some division between the literal, i.e. linguistically encoded, meaning of utterance types and the non-literal meaning tokens of that type can have on particular occasions of use. For some recent discussion, see for example Bach 2001, García-Carpintero 2001, Predelli 2005, Recanati 2004 or Wilson and Sperber 2002.
} 


\section{Essentially rule-governed action}

Many actions are essentially rule-governed and in that sense conventional. For example, buying a newspaper, scoring a goal or playing the ball out in football, signing an assured shorthold tenancy agreement, expelling someone from the Reform Club, registering an objection to a planning application, betting ten pounds on Ronnie O'Sullivan to win. What these actions have in common is that they are, or are part of, activities that are constitutively governed by norms and conventions. They depend for their existence on certain human-made rules. For example, without the 1988 Housing Act the action of signing an assured shorthold tenancy would not exist, and without the rules of football, nothing would count as playing the ball out in football. ${ }^{4}$

In my discussion, I will distinguish two different kinds of rules: implementation conventions and constitutive norms. Let me explain. Every rule-governed activity must have a medium in which it is implemented. For example, any (concrete) game of chess must be implemented in some medium, such as a wooden chess-board or constellations of digital encodings. Because any conventional action depends for its existence on certain rules, performing the action must be constituted by some other action or procedure that does not itself depend for its existence on the same rules. To see this, try to imagine a conventional action which is not implemented non-conventionally. Suppose action A exists only because of certain rules $\mathrm{R}$ a certain group adheres to. But there is no action independent of $\mathrm{R}$ that constitutes performing $\mathrm{A}$. This seems incoherent, for how would the members of the group perform A? The only sense in which rules can bring about the existence of new kinds of action is this: the rules stipulate that a certain type of independently existing action is to have a certain status, a status which is further specified by a number of norms. This means that for any conventional act-type $C$, there must be a certain non-conventional act-type $N$ performing which counts as performing $C$. What I call "implementation conventions" lay down which non-conventional procedure $N$ counts as performing $C .^{5}$ Thus, for example, handing a coin to the newspaper man while grabbing a newspaper with the other hand counts as buying a newspaper. Turning the doubling die in a certain way in the course of a game of backgammon counts as doubling.

Implementation conventions thus stipulate which non-conventional procedure counts as the conventional act in question. However, they do not yet introduce any norms properly so-called, namely obligations, permissions or rights, i.e. the sort of convention that can be violated. In addition to the stipulation of what counts as performing $C$, there also need to be constitutive norms that make up the normative significance of $C$. For example, in addition to knowing what type of conduct counts as a foul in football, we also need to know what obligations and rights arise from a foul. Someone who didn't know these things wouldn't fully understand the conventional act of committing a foul in

\footnotetext{
${ }^{4}$ Compare Searle 1969, pp. 33-42. Austin (1962) introduced the idea of language as conventional action into the philosophical discussion. Strawson (1964) claims that some speech acts are constitutively rulegoverned, reserving for other speech acts a Gricean treatment in terms of communicative intentions. See also Millar 2004 for a similar account of essentially rule-governed activities (practices).

${ }^{5}$ When calling $N$, the action that constitutes $C$ "non-conventional", I mean that $N$ is independent of the conventions essential for $C$. It is of course possible (and frequent) that $N$ is itself a conventional action dependent on other conventions (e.g. handing over money to a policeman when he stops you counts as an attempt to bribe him-handing over money is itself an action type which constitutively depends on conventions).
} 
football. Similarly, the implementation convention which says that handing over a coin counts as buying the newspaper does not exhaust the constitutive rules concerning that activity. Buying a newspaper crucially gives rise to certain rights and obligations: the buyer acquires property rights over the copy he bought. I call these norms "constitutive norms".

There can be a certain arbitrariness about the implementation conventions, i.e. the rules that say which non-conventional procedures count as the conventional action in question. That's why I call them "implementation conventions". Sometimes, these conventions are not essential to an act. In other words, a different non-conventional procedure could have been taken to count as a given conventional act $C$, and it would still have been $C$. For example, backgammon could be implemented in a very different medium, including (very uncomfortably) in a purely one-dimensional medium. It would still be backgammon. Another example: handing a credit-card to the newspaper man and signing the slip he hands back to you also counts as buying a newspaper. This could have been the only procedure that counts as buying a newspaper, if the implementation conventions of buying had been different. It would still have been the act of buying a newspaper. In other cases, one particular non-conventional implementation is essential to a conventional act type or activity.

\section{Asserting as rule-governed activity}

Linguistic communication has an obvious similarity with the conventional activities described above. It seems that in linguistic communication going through certain procedures or forms of conduct counts as making one of a range of moves, and making these moves has a certain normative significance. For example, going through the procedure of uttering "Hello" (in the right tone of voice) when addressing someone counts as greeting that person, and greeting a person has a certain normative significance (e.g. failure to greet may be regarded as offensive; being greeted by someone creates the expectation that one greet back etc). Another example: going through the procedure of uttering "The train is late.", in normal circumstances, counts as asserting that the train is late. The normative significance of this action consists in it bringing about certain rights and obligations concerning the asserter and his or her audience. For example, the assertion might introduce the conversational background information that the train is late, with the result that this may be presupposed in subsequent utterances. Another kind of normative significance is not purely linguistic: if a member of the audience of this assertion were to miss the train because the train was on time but he or she was relying on the assertion that the train was late, then this member of the audience would have a right to reproach the asserter, or to impose other sanctions. Whether and how he or she may express his or her reproach, or what sanctions would be appropriate, are ethical questions, not linguistic ones.

One of the guiding ideas of this paper is that we ought to take seriously the analogy of linguistic communication with other rule-governed activities. The following aspect of the analogy is especially important for my purposes. Consider a game like football. It is useful to distinguish objectives internal to the game from the external aims which are pursued through playing the game. Thus scoring goals and winning are objectives which are internal to the game, while entertaining oneself or others, improving one's health or 
earning money are aims that are external to the game and that can be pursued by making moves within the game. Thus playing a game is not only non-conventionally implemented, it can also itself implement actions that are not themselves part of the game, such as enjoying oneself or earning money. I believe that there is a similar distinction in the case of linguistic communication. On the one hand, we make certain linguistic moves which have certain purely linguistic purposes and consequences. On the other hand, we pursue non-linguistic goals by making these linguistic moves. For example, I may pursue the linguistic purpose of manipulating the common ground of a conversation in order to serve the extralinguistic aim of transmitting information. I believe that a distinction between innerlinguistic and extra-linguistic purposes is crucial to understanding linguistic communication. My aim in this paper is specifically to carve out a role for assertion (and other illocutionary acts) as an innerlinguistic move which cannot be fully understood in terms of communicative intentions.

Just as one can distinguish between innerlinguistic and extra-linguistic purposes, one can also distinguish between purely linguistic norms and other social norms, such as legal, moral or prudential norms. It is difficult to draw this distinction and this is one reason why it is difficult to say what precise set of norms is constitutive of assertion understood as an innerlinguistic, conventional act. For example, asserting that McDonalds food is unhealthy may constitute libel, and committing libel is a conventional act that can have drastic normative consequences. ${ }^{6}$ However, intuitively the norms concerning libel are not themselves constitutive of assertion. ${ }^{7}$

A number of theorists share the view that assertion is essentially normative. (Though they do not, as I do, distinguish assertion as a conventional act from assertion as an act performed with certain communicative intentions.) For example Williamson (1996 and 2000, chapter 11) suggests that the only norm constitutive of assertion is the norm that prohibits asserting propositions one does not know. ${ }^{8}$ Brandom $(1983,1994)$ claims that asserting a proposition brings about an obligation of the asserter to justify her assertion if challenged and it also brings about a permission for the audience to rely on the proposition asserted as a premiss. Brandom does not distinguish general social norms from specifically linguistic ones.

The framework in my view best suited to the idea of conventional (literal) assertion is that pioneered by Stalnaker (1973, 1974, 1978, 2002), and Lewis (1979). According to this framework, assertions and other linguistic acts have a characteristic effect on the "context" or "conversational score" of a conversation. In my view, modification of the

\footnotetext{
${ }^{6}$ Some assertions about McDonalds by London Campaigners Dave Morris and Helen Steel led to the longest trial in English legal history, the "McLibel" case in 1994-6. See www.mcspotlight.org or the recent documentary film for more information.

${ }^{7}$ Though the norms and conventions of assertion may conversely play a role in the constitutive norms of libel: to commit libel it may be sufficient to make assertions with a certain type of content.

${ }^{8}$ More precisely, Williamson argues that the above-mentioned norm is the only non-derivative norm in the form of a conditional prohibition which governs all assertions and does not govern all instances of any other illocutionary act type.

In my view, saying merely that asserting something unknown is wrong in some unspecified sense (2000, p. 140), is not to say much about the normative significance of making assertions. Full understanding of the activity of asserting would require knowledge of a host of further normative facts, no doubt some of them not specific to assertion and some of them not purely linguistic.
} 
conversational score can be seen as the internal aim of linguistic communication and communicators pursue this internal aim in order to further their non-linguistic aims. Conventional (literal) assertion is an innerlinguistic move the normative role of which is completely characterizable by specifying the rules by which the conversational score changes. In particular, these rules will include the rule that if a proposition is asserted then it is added to the conversational score unless the assertion is challenged. However, this is not the place to defend this account in detail. ${ }^{9}$ The purpose of this paper is merely to argue that a notion of assertion as conventional action (literal assertion) has a number of theoretical attractions and can be defended against some objections in the literature.

In the current context, I will therefore operate with a schematic formulation of an account of assertion as an essentially normative, conventional action. Let's suppose, for the rest of this paper, that the account of the norms constitutive of assertion has the following form:

(A1) For all $p$, necessarily, if a speaker has asserted that $p, \mathrm{~N}$.

where "N" is schematic for whatever the constitutive norms of assertion are. 10

I have not yet said anything about the implementation conventions concerning assertion, i.e. those conventions that say which procedure counts as asserting $p$ (for variable $p$ ). According to Sadock and Zwicky (1985), all natural languages contain some distinction between what they call "sentence-types", namely declarative, imperative and interrogative. Many theorists call the features of sentences that indicate illocutionary force "moods" (whatever those features may be). This is slightly misleading because "mood" originally referred to certain inflectional properties of verbs (see Harnish 1994, p. 408-9). It is clear that there are many languages, including English, where the function of indicating illocutionary act types is not implemented by a systematic inflectional feature of the principal verb, even though some systematic such modifications are quite typical. Nevertheless I will follow custom and speak of moods as the conventional indicators of force, in whatever way they are implemented. That moods exist and are somehow correlated with the force of sentences is, I believe, undeniable (see again Sadock and Zwicky 1985 for a cross-linguistic study). Even Davidson admits that there is

\footnotetext{
${ }^{9}$ Pagin forthcoming articulates a recipe for generating counterexamples to any account that makes a certain social normative fact constitutive of asserting that $p$. The recipe is to construct a complex performative that brings about the same social normative fact, but which, arguably, cannot be used to assert that $p$. I do not here have the space to do justice to this objection. At this point let me just briefly indicate two possible lines of reply: First, the conventionalist could insist that if Pagin's complex performative does indeed bring about the same normative fact, then it constitutes an alternative way of making assertions. A second, perhaps better, line of response would make it constitutive of assertion that the relevant normative fact be brought about by a simple force-indicating device specifically designed to bring about such facts.

${ }^{10}$ The necessity operator in (A1) reflects the fact that the norms schematically mentioned on the right hand side of the conditional are essential to assertion. There may be a problem about requiring that the constitutive norms of assertion be expressed in this form, for some theorists (e.g. Williamson 2000, GarcíaCarpintero 2004) use an obligation operator to express the norms governing assertion, e.g. "One must: assert $p$ only if one knows $p$ ", or equivalently: "it is prohibited to assert $p$ while one does not know $p$ ". But it is not obvious that these forms are equivalent to "Necessarily, if one asserts $p$, then if one does not know $p$ one is violating the norms of assertion". But I believe that this subtlety can be passed over in the current discussion. Thanks to Krister Bykvist for discussion. See Broome 1999 for a general discussion of the differences between wide-scope and narrow-scope norms.
} 
some conventional correlation between moods and illocutionary force (1979, pp. 114, 116). What is controversial is whether mood can conventionally indicate that an utterance has a certain force in the same way in which, say, use of the pronoun "I" can conventionally indicate reference to the speaker, or the procedure of writing one's name on a piece of paper under certain conditions counts as signing a contract. I shall defend this more controversial thesis, namely that there are implementation conventions of this sort in the case of assertion:

(A2) There are conventional assertoric force indicators which reliably indicate that an utterance counts as an assertion (as characterised by the correct instance of (A1)).

Let us call any account of assertion that combines an instance of (A1) with (A2) a "conventional account" (or "C-account") of assertion, and any notion of assertion that conforms to a conventional account a notion of "conventional assertion", or "CCassertion". The aim of this paper is to advance some considerations in favour of employing a notion of C-assertion.

Strawson (1964), characterizes a notion of essentially conventional speech act that is very close to what I have been trying to characterize above. He draws a distinction between two types of speech act. One type is "essentially conventional" speech acts, which "could have no existence outside the rule- or convention-governed practices and procedures of which they essentially form parts" (1964, p. 36). Strawson lists marrying, redoubling, giving out, pronouncing sentence, bringing in a verdict. Speech acts of this kind are "standardly intended to further, or affect the course of, the practice in question", but they can in fact be performed unintentionally ("A player might let slip the word "redouble" without meaning to redouble; but if the circumstances are appropriate and the play is strict, then he has redoubled" $(1964$, p. 36)). He clearly identifies something analogous to (A2) as the mark of these essentially conventional acts:

... the act is identified as the act it is just because it is performed by the utterance of a form of words conventional for the performance of that act. Hence the speaker's utterance is not only intended to further, or affect the course of, the practice in question in a certain conventional way; in the absence of any breach of the conventional conditions for furthering the procedure in this way, it cannot fail to do so. $(1964$, p. 36)

Thus Strawson's essentially conventional illocutionary acts are essentially part of a ruleor convention-governed practice (which corresponds to (A1) above), and there are also overt procedures which, when performed under the right circumstances, are sufficient for performing the act in question. Strawson does not mention illocutionary acts like assertion. It is the current aim to argue that there is a useful notion of assertion as essentially conventional act, i.e. of C-assertion. ${ }^{11}$

\footnotetext{
${ }^{11}$ The other type of illocutionary act Strawson speaks about includes acts that are not essentially conventional, but which require uptake by the audience for their occurrence. The example he gives is Grice's meaning $_{\mathrm{NN}}$, which, he believes, captures a pretheoretical notion of "attempting to communicate". There are no other examples; assertion, question, command are not mentioned.
} 
Before moving on to intentional notions of assertion, I would like briefly to mention Dummett's views on assertion, which, I believe, are a good example of a Caccount. In the chapter on assertion of his Frege: Philosophy of Language, Dummett distinguishes two approaches to assertion:

We ... tried to specify which [utterances] constituted assertions by reference to the intention of the speaker. Rather, the correct approach is to consider utterances as conventionally demarcated into types, by means of the form of linguistic expressions employed, and then to enquire into the conventions governing the use of the various types of utterance. (p. 302)

According to the first approach, the act of asserting is defined in terms of certain speaker intentions. The same sentence with the same conventional content can be uttered with various different concomitant intentions. Whether an utterance is an assertion depends on the nature of these concomitant intentions. For example, making an assertion might, on one version of this approach, require that the speaker intends to say something true. Or on a different version, it might require that the speaker intends the audience to believe the speaker to intend to be saying something true. By contrast, according to the second approach, "it is irrelevant what intentions the person speaking may have had" (p. 302). Dummett defends the latter, conventional approach.

\section{Assertion as a matter of speaker-intention}

C-assertion is an essentially conventional or social act which could be performed inadvertently, by virtue of being a participant in a conversation and exhibiting the kind of conduct that conventionally counts as C-asserting. Many theorists, especially Grice and many influenced by him, have a very different conception of assertion and illocutionary force. ${ }^{12}$ These theorists prefer an intentional account of assertion (or I-assertion). On an Iaccount, assertion (as well as the other illocutionary acts) are essentially utterances made with certain audience-directed intentions. One kind of I-account says that in order to assert that $p$ one needs to speaker-mean that $p$. This involves that the asserter have intentions regarding some perlocutionary effect on the audience. Asserting that $p$, on such a view requires producing some perceptible stimulus with the intention of getting one's audience to believe that (one believes) $p .{ }^{13}$ Following Grice, the intention to get the audience to believe (that one believes) $p$ must also be accompanied by the intention that this belief arise in part because the audience recognises the first intention. But the important unifying feature of all I-accounts of illocutionary forces is that each illocutionary act-type requires that the asserter have certain audience-directed communicative intentions. For example, it may require the asserter's intention that the

\footnotetext{
${ }^{12}$ A good example is Grice 1989, p. 123:

D1: "By (when) uttering x U meant that ${ }^{*}{ }_{\psi} p "=d f$. " $(\exists A)(U$ uttered $x$ M-intending [i] that A should think $\mathrm{U}$ to $\psi$ that $\mathrm{p}$ and [in some cases only, depending on the identification of $*_{\psi} \mathrm{p}$ ] (ii) that $\mathrm{A}$ should, via the fulfillment of [i], himself $\psi$ that $p$ )."

In Grice's theory, the analogues of asserting that $p$, asking whether $p$, and ordering that $p$ are: meaning that $1-\mathrm{p}$, meaning that ?p and meaning that ! $\mathrm{p}$, each of them associated with some "corresponding propositional attitude" (123), such as believing or intending.

${ }^{13}$ The modification added in brackets was added by Grice in response to some difficulties. I discuss this modification of the Gricean intentions below in $\$ 6$.
} 
audience believe what was asserted or that they make true what was requested or that the audience answer what was asked, etc. ${ }^{14}$

In order to illustrate the difference between $\mathrm{C}$-accounts and I-accounts of assertion, consider the following two utterances of the same sentence:

(1) The door is open. (as uttered in response to the question "Why is there such a draft?")

(2) The door is open. (as uttered in order to get the audience to shut the door, in the full knowledge that the audience already knows, and knows that the speaker knows, that the door is open.)

Utterance (1) will qualify both as an I-assertion and as a C-assertion: the speaker has asserted that the door is open. However, I-account and $\mathrm{C}$-accounts will diverge on whether utterance (2) is an assertion. Utterance (2) is not intended to get the audience to believe (that the speaker believes) that the door is open and is clearly intended by the speaker to get the audience to close the door. A similar effect could be brought about by an utterance of "Shut the door!". This may lead those with an I-account of assertion to argue that utterance (2) is an order or a request rather than an assertion. For the speaker does not have the communicative intentions required for making an I-assertion, but she does have intentions sufficient for a making a request. C-theorists of assertion, by contrast, might hold that utterance (2) is an assertion, because it is the performance of an act type that conventionally counts as an assertion, namely the utterance of a sentence in the assertoric mood. But nevertheless, by asserting that the door is open, the speaker might achieve certain perlocutionary effects, and might do so intentionally. She might intend to get, and succeed in getting, the audience to infer that she wishes the door to be shut and thereby get the audience to shut the door. Thus a C-theorist might hold that (2) is both a C-assertion and an I-command.

\section{The argument from indirect speech acts}

Cases like (2) might be used, by adherents of I-accounts of assertion and command, to argue that there are no conventional force indicators, i.e. no forms of conduct that conventionally count as making assertions, issuing commands etc. For no linguistic convention can dictate what communicative intentions speakers have when they use sentences. Davidson seems to argue in just this way:

... there are many utterances of indicative sentences that are not assertions, ... and assertions may be made by uttering sentences in other moods. ... And similarly for the other moods; we can ask a question with an imperative or indicative ("tell me who won the third race", "I'd like to know your telephone number"), or issue a command with an indicative ("In this house we remove our shoes before entering"). (1979, p. 110)

\footnotetext{
${ }^{14}$ Lewis (1975, p. 172) has a slightly divergent intentional account of assertion. He proposes in effect that assertoric sentences of a language are the ones which speakers try to use only when their contents are true and whose contents audiences tend to believe (with a few exceptions - p. 165).
} 
However, it is quite clear that this argument only affects the question whether $I$-assertion is conventionally indicated by the indicative mood. The hypothesis Davidson wants to disprove is the ((A2)-like) hypothesis that

(H) The assertoric mood is a conventional indicator of assertoric force.

i.e. the view that by an implementation convention utterances of an assertoric sentence (under certain normal conditions) count as assertions. One of the purported counterexamples is an utterance of the assertoric sentence "In this house we remove our shoes before entering" which is made with the overt intention of getting the audience to remove their shoes, i.e. it is an I-command. The view that this is a counterexample to $(\mathrm{H})$ relies on two assumptions. First, the assumption that an I-command cannot also be an Iassertion. This is not obvious, but let's grant it for the sake of argument. The second assumption: "assertion" in $(\mathrm{H})$ is to be read as meaning I-assertion, so that certain communicative intentions in the asserter are required for assertion.

Even if, on these assumptions, the utterance of "In this house ..." is a counterexample to $(\mathrm{H})$, it is not yet a counterexample to a C-reading of $(\mathrm{H})$. Those who believe that uttering an assertoric sentence counts (under certain normal conditions) as an assertion have in mind C-assertion, not I-assertion. Thus Davidson's cases are not counterexamples to the hypothesis that an utterance of a sentence in assertoric mood (under certain normal conditions) counts as an assertion. When the convention-theorist claims utterance (2) is an assertion and Davidson says utterance (2) is not an assertion, they do not mean the same with "assertion". One is using an I-notion, the other is using a $\mathrm{C}$-notion of assertion. It might therefore appear that the debate about whether there is a conventional sign for assertoric force is based on a terminological confusion.

But the issue is not just terminological. One substantial question is whether a theory of linguistic communication can dispense with one or the other of the two notions of assertion. I believe that both notions are probably indispensible. ${ }^{15}$ Because the $\mathrm{C}$-notion is the one whose legitimacy I am defending here, I shall offer in the next section some reasons for thinking that $\mathrm{C}$-assertion is an indispensible notion.

The above discussion was a simplification of Davidson's argument, for Davidson is in fact not a clear exponent of an I-account of assertion (and the other illocutionary types). It will be useful to examine in detail the notion with which Davidson operates. Davidson explicitly denies a Gricean I-account of assertion:

The asserter may or may not, in making an assertion, intend to cause his hearer to believe he believes what he says. (1982, p. 268)

Nevertheless in some places, Davidson seems to subscribe to some sort of I-account of assertion, for he requires certain speaker intentions that preclude inadvertent assertion:

... in making an assertion, the asserter must intend to make an assertion, and he must intend that this intention be recognized by his audience. (1982, p. 269)

and

\footnotetext{
${ }^{15}$ Segal $(1990, \S I V)$ seems to agree: he distinguishes the semantic (literal) force of an utterance from its pragmatic force.
} 
Of course assertion or command must be intentional, as must meaning in the narrow sense. But it is part of the intention that the act should be interpreted as assertive or commanding, ... (1979, p. 114)

However, there are other remarks in which he seems to support a C-account:

Making an assertion is, then, like playing a game in a respect in which speaking the truth is not: there is a public presumption of purpose. (1982, p. 268)

and

To assert is, among other things, to represent oneself as believing what one asserts. (1982, p. 270)

One might think that it is possible unintentionally to represent oneself as believing something, and inadvertently to make a move that carries a public presumption of a certain purpose. This is why the last two remarks might seem in tension with two preceding remarks. However, there is no such tension if Davidson believes that publicly representing oneself as believing something requires that one have the intention of doing so. If this exegesis is correct it explains why Davidson does not want to allow a conventional sign of assertion: he believes that assertion essentially involves certain communicative intentions, for example the intention to represent oneself as believing and the intention that this be recognised. However, there cannot be a convention that connects "what may always be secret ... with what must be public" (1982, p. 270). So there cannot be a conventional indicator of assertoric force.

\section{Literal content and literal force}

Before discussing another Davidsonian argument in section 7, I would like to provide some arguments why a theory should (possibly in addition to any I-notions of illocutionary force) employ a C-notion.

Consider the following utterances:

(3) You are the salt in my soup.

(4) Of course I'll pay $€ 199$ for a hair cut. I can't think of a better way of spending my money.

The distinction between literal and non-literal meaning seems very well suited to explain how these utterances can serve communicative aims. (3) is literally an assertion of the obviously false proposition that the adressee is the salt in the utterer's soup. The audience knows this and will be able to work out the content the utterer intends to communicate, for example that the addressee is in some sense indispensible for the utterer. In whatever way the audience computes the non-literal content: they need the literal content of (3) (or at least the literal content of the components of $(3)^{16}$ ) as initial input. It seems impossible to explain how communication could succeed otherwise in such cases. Similarly, the two propositions literally asserted in (4) are needed by the audience to work out the non-

\footnotetext{
${ }^{16}$ See, e.g., Wilson and Sperber 2002.
} 
literal content. The view that in such cases communication relies on literal, semantically encoded meaning as an essential step in interpretation seems compelling. ${ }^{17}$

If we accept the theoretical justification of a distinction between linguistically encoded and actually communicated contents (or subcontents), then by analogy we should explain why (2) is an I-request on the basis of the fact that (2) is a C-assertion. Here is how this might go: (2) is a $\mathrm{C}$-assertion of a proposition that is already known by all participants and known to be known by all of them. For this reason the point of (2) cannot be to I-assert that proposition. Suppose, for example, that it is part of the conversational score or common ground (accepted by all participants) that it is desirable that the door be shut if open. Under those conditions, (2) can work as an I-request that the door be closed, for the speaker has brought it about that it is now part of the common ground of the conversation that the door is open. Adding this information to the common ground will make it part of the common ground that the door ought to be shut by someone now. This will provide a motivation to shut the door, or, if perhaps it is also part of the common ground that one particular member of the audience is responsible for shutting the door, then that member will be motivated. This is just one possible account of the process that might allow a hearer to interpret (2) as an I-command. But any adequate account will need to make reference to two elements: (i) the sentence's conventional assertoric force (it is not a coincidence that the sentence uttered is assertoric) and (ii) some contextual information that encourages the interpretation of (2) as an I-command.

Element (i) might be disputed in the following way. All an adequate account needs to say is that (2) expresses the proposition that the door is open, thus making the obvious fact that the door is open salient and thereby triggering the background imperative that the door be closed if open. However, this account cannot explain why it is not equally appropriate to utter an interrogative sentence with the same content. If, in this situation, a literal question is to function as an I-command to close the door, then it would be the Iquestion whether the door is closed, not the I-question whether the door is open. If you have doubts about this consider a parent who wants to get a child to do his homework. The parent might say: "You have not yet done your homework." or "Have you done your homework?" but surely not "Have you not done your homework?".

It is also possible to provide other examples where literal force undeniably plays a role. Consider the following utterance:

(5) Do fish swim? (uttered in response to the question whether politician $\mathrm{X}$ is corrupt)

Clearly, the utterer of (5) is not I-asking whether fish swim. Nevertheless, the information that (5) is a question in some sense (i.e. a C-question) is clearly needed to interpret the utterance as suggesting that the question asked has an obvious answer.

\footnotetext{
${ }^{17}$ Even Davidson (1986) is forced to admit that we need "temporary theories" as an interpretative starting point, and even Sperber and Wilson (1995) assign a clear role to semantically encoded literal meanings, though they deny that the literal content of (3) as a whole needs to figure in the interpretation process (Wilson and Sperber 2002).
} 
In sum: if cases like (3) and (4) provide a motivation for admitting literal contents (be it of entire sentences or their subsentential constitutents), then cases like (2) and (5) surely provide motivation for admitting literal forces. It seems to be generally accepted that semantically encoded literal contents (or subcontents) play a key role in non-literal communication. However, the case is just as good for semantically encoded literal illocutionary forces. Any pragmatic account of how an audience can arrive at an interpretation of (2) as an I-command will start with some literal meaning as input. It seems to me that the case for literal forces as input to this pragmatic process is just as compelling as the case for literal contents (subcontents) as a starting point in cases (3) and (4).

This leads me to a related consideration in favour of $\mathrm{C}$-assertion and $\mathrm{C}$-forces in general. It seems quite clear that moods as they actually occur in natural languages (i) have some conventional significance and (ii) this conventional significance plays a role in the defeasible correlation often observed between moods and illocutionary forces in the Isense. (This is observed, for example, by Davidson 1979, p. 115-6.) We ought to explain the conventional significance mentioned in (i), and this should provide a basis for explaining (ii). Moods that conventionally indicate C-forces would be a way to do both these things. 18

Let me flesh out how this might go. Suppose we have a characterization of the normative role of $\mathrm{C}$-assertions (some instance of (A1)). If this characterization is adequate, it will explain why, very often, speakers make C-assertions in order to make Iassertions. Thus, for example, Williamson might attempt to explain why we very often perform an act that is governed by his knowledge rule ("Do not assert what you do not know!") in order to I-assert. For example, someone might C-assert that Kripke works at CUNY because they want their audience to believe that Kripke works at CUNY (i.e. they are I-asserting that Kripke works at CUNY). This would be an appropriate means to that end because $\mathrm{C}$-asserting that $p$ generally exposes one to criticism should it turn out that one does not know that Kripke works at CUNY, so the audience may assume that one at least has reasonably good grounds for believing that one knows that Kripke works at CUNY now.

Someone following a Brandomian line might say that $\mathrm{C}$-assertion involves the obligation to justify what is asserted when asked to do so, and the license of recipients to rely on what has been asserted as a premiss. On this view, performing the conventional act of C-asserting that Kripke works at CUNY is again a good means for achieving the aims characteristic of I-assertions that Kripke works at CUNY, namely getting the audience to believe it.

A third account (the kind of account I currently favour) would take C-assertion essentially to bring about a change in the conversational score (common ground). For example, if it is C-asserted that Kripke works at CUNY and the assertion is not challenged, then it becomes part of the conversational score that Kripke works at CUNY (and if the score already contains the proposition that Kripke works exclusively at Princeton, then this part of the score will have to be revised). On this view, participants of conversations use the conversation game to gain information and to influence the beliefs

\footnotetext{
${ }^{18}$ Something along these lines is Segal's argument for his semantics of s-forces, see his 1990, p. 103-4.
} 
of others. Thus, participants may come to believe what others have asserted because these others have exposed themselves to possible criticism should their assertions turn out to be unfounded. Or participants may reasonably expect an audience to come to believe what they have asserted precisely because the audience knows that the asserter has exposed him or herself to criticism should his or her assertion turn out to be unfounded.

On all these views of $\mathrm{C}$-assertion we have an explication of (i) the conventional significance of the moods and (ii) an explanation of why the moods are correlated significantly (but imperfectly) with corresponding I-acts.

\section{Meaning and use: escaping the complex-intentions trap}

Another considerable advantage of a notion of $\mathrm{C}$-assertion is that it helps explain the relation between linguistic meaning and language use. It does so at the cost of giving up the project of reducing linguistic meaning to the mental states of individuals, but in favour of an approach that operates with an unreduced notion of norm.

It is attractive and plausible to suppose that the linguistic meaning of utterance types is determined by the use speakers make of these types. Several philosophers have made attempts at explaining this relation of determination, Grice and Lewis among them. Let us briefly consider Grice's attempt at explaining sentence meaning in terms of speaker meaning.

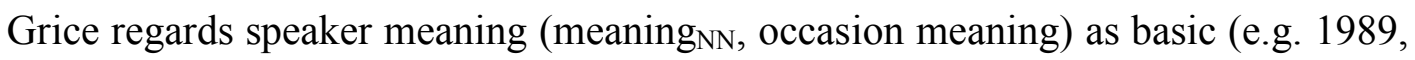
p. 117), and attempts to elucidate the conventional meaning of utterance types in terms of this basic notion. The rough idea is that an utterance type means that $p$ just if speakers use it to mean that $p$. In refining this rough idea, Grice faces a number of problems.

The first problem is that of constructing the right notion of speaker meaning. If the idea is that roughly an utterance type means something just if speakers use it to mean that thing, then the notion of speaker meaning must somehow capture (at least) those uses that are meaning constitutive, i.e. "central" uses. Grice himself operates with an intuitive constraint on speaker meaning. But it is clear that if his attempt to define sentence meaning in terms of speaker meaning is to succeed, the notion must also be such that central (or meaning constitutive) uses are cases where speaker meaning and sentence meaning coincide. Now, the original (1957) account defined speaker meaning along these lines:

(SM1) An utterer $U$ means that $\mid-p$ by uttering $\mathrm{x}$ just if there is an audience A such that $\mathrm{U}$ intends $\mathrm{A}$ to come to believe $p$ (at least partly on the basis of recognising that intention).

But there are counterexamples, such as the following utterance:

(6) The Battle of Hastings was fought in 1066. (uttered by a pupil in an exam.)

Clearly, (6) is among the many uses of "The Battle of Hastings was fought in 1066." in virtue of which that utterance type conventionally means what it does. It is a central use. In Gricean terms, (6) is intuitively a case of speaker meaning. But it is not a case of speaker meaning as defined by (SM1) because the pupil does not intend the examiner to come to believe that the battle was fought in that year (for the pupil believes that the teacher already knows this). Cases like (6) forced Grice to revise (SM1). Grice's revision 
consisted in requiring only an intention that the audience come to believe that the speaker believes what was said:

(SM2) An utterer $U$ means that $\mid-p$ by uttering $\mathrm{x}$ just if there is an audience A such that $\mathrm{U}$ intends $\mathrm{A}$ to come to believe that $\mathrm{U}$ believes that $p$ (at least partly on the basis of recognising that intention).

But (SM2) faces new counterexamples. Consider:

(7) I didn't do it. (as uttered by a prisoner in an interrogation when he knows that he cannot bring it about that the interrogators believe that he believes what he has asserted.)

Again, (7) is intuitively a case of the speaker meaning that the speaker didn't do it. Or in our terms: (7) would seem to be one of the central uses of the utterance type "I didn't do it." in which speaker meaning and sentence meaning coincide, i.e. what is meant is that the speaker didn't do it. But according to (SM2), (7) does not speaker-mean that.

One could at this point introduce further revisions of (SM2). However, it is not clear that there will not be further counterexamples - even though counterexamples will be increasingly complex. Further revisions along the same lines will make the account of speaker meaning so complex, that the question of the theoretical status of these Gricean reconstructions becomes more urgent. At the very least, there seems to be no principled way to decide at which level of complexity to stop revising. Grice himself admits that "a very much more complicated definition" (p. 124) would be required to meet all counterexamples.

The second problem Grice has to solve is that of specifying the exact connection between speaker meaning and sentence meaning. His "first shot" is to say that a sentence means that $p$ in a speaker's idiolect just if that speaker has a "policy (practice, habit)" (p. $125)$ to speaker-mean that $p$ with it. But the "just if" here is problematic. ${ }^{19}$ For another sentence may have the same meaning or the same sentence may have another, additional meaning (i.e. be ambiguous in a wide sense). Grice therefore introduces the notion of "having a procedure in one's repertoire" (p. 126). Thus, he proposes the folloiwng definition:

D2: "For U utterance-type X means (has as one of its meanings) ' ${ }_{\psi}{ }_{\psi} p$ "” $=$ df. "U has in his repertoire the following procedure: to utter a token of $X$ if $U$ intends (wants) $A$ to believe that $U \psi$-s that p. $(1989$, p. 126 , with slight alteration for better readability)

Grice then goes on also to define a notion of utterance type meaning in a group, as opposed to the idiolect of one speaker. His idea is that utterance type meaning in a group is constituted by "some (many) members" of the group having the relevant procedure in their repertoires and retain the procedure in their repertoires on the assumption that at least some other group members do likewise.

While I believe that Grice is on the right track with his notion of a group having a procedure in their repertoire (my proposal has some similarities with this idea), I do believe that the elucidation of sentence meaning in terms of language use can be

\footnotetext{
${ }^{19}$ In fact, Grice's first shot involves only an "if". But his subsequent discussion is conducted in such a way as to suggest that he meant "if and only if" (see 1989, p. 126).
} 
substantially facilitated by operating not with a purely intentional notion of speakermeaning (and in effect of the various illocutionary acts), but rather with conventional notions. The main gain is that (potentially endless) revisions of (SM1) in the light of cases with unusual communicative intentions are rendered unnecessary. If we seek a definition of $\mathrm{C}$-assertion along the lines proposed in section 3 above, all we need to specify is the normative role $\mathrm{C}$-assertions play within the conversational game. We can then say that a sentence $s$ is conventionally assertoric of $p$ (its use counts as a $\mathrm{C}$-assertion that $p$ ) in a group, just if that group treats utterances of $s$ as $\mathrm{C}$-assertions, i.e. if the relevant norms are in force in that group. A group treating an utterance as a C-assertion, and the norms being in force in the group, will ultimately be a matter of the actions and intentions of individual speakers. But we need not provide a reductive account of norms in order to draw explanatory benefit from these claims about norms.

It is clear that such an approach can no longer be treated as a reduction of sentence meaning to what individual speakers mean by uses of sentences. But it is equally doubtful whether Grice's final proposal in terms of "having a procedure in their repertoires" can be so treated, or, at any rate, if this attempt would be a successful reduction.

A similar story can be told about David Lewis's attempt to relate sentence meaning to language use (i.e. his attempt to explicate the actual language relation (Lewis 1975). Lewis's account is a descendant of Grice's. However, Lewis employs a powerful gametheoretical notion of convention which is explicable in terms of the beliefs and desires of the members of the groups in which the convention prevails. Let me transpose freely. Lewis believes that a group uses a sentence as assertoric of $p$ just if they have a convention (i) to try to use the sentence only if they believe that $p$ and (ii) to come to believe that $p$ upon hearing an utterance of the sentence. Now, on Lewis's definition of a convention each convention is a regularity that is uniformly conformed to "with at most a few exceptions" (1975, p. 165). This account faces objections that are analogous to the counterexamples to Grice's account. Of course there are more than a few exceptions to the rule that speakers try to utter a sentence that is assertoric of $p$ only when they believe $p$. Again, the account can be modified, but it is not clear that this will solve the problem short of major complication. ${ }^{20}$ A conventional account of $\mathrm{C}$-assertion, $\mathrm{C}$-question and $\mathrm{C}$ command can avoid these complications (at the price of abandoning any reductive project): the sentence is assertoric (interrogative, imperative) of $p$ just if utterances of the sentence are governed by the norms characteristic of assertion that (question whether, command that) $p$.

\section{Jokes, stories and theatre}

In addition to considerations to do with indirect speech acts (such as (2) above), Davidson $(1979,1982)$ has also objected to conventional force indicators on principled grounds. I shall now discuss this objection.

Davidson argues that there could not be a sentence-feature that conventionally marks assertoric force. For, he says, "every joker, storyteller and actor will immediately take advantage" and simulate assertion (1979, p. 113). His idea is that jokers, storytellers

\footnotetext{
${ }^{20}$ See Kölbel 1998 for a detailed exposition of, and attempt to solve, this problem. See also Hawthorne 1990, 1993 and Lewis 1992.
} 
and actors do not make assertions and are therefore living counterexamples to the view that there are illocutionary force indicators.

At first sight Davidson's point seems compelling: jokers, storytellers and actors don't seem to be asserters, yet they use assertoric sentences, and they would use any other conventional force-indicator, if there were any. Some reflection, however, shows that it is not at all clear that jokers do not make genuine assertions. In the fictional case it is more plausible to say that these are instances of assertoric utterances without assertoric force, but still far from mandatory. Let me consider some ways in which a C-account can deal with the various cases.

By way of preparation, let us consider an analogous argument - if Davidson's argument works then this analogous argument should work as well. It's an argument for the view that there cannot be a procedure that conventionally counts as signing a contract. The argument goes like this: suppose there were such a procedure. Then it would immediately be exploited by jokers, frauds and actors. They would use the procedure even though they aren't signing a contract. They are just pretending to sign a contract.

Since we know that there are procedures that conventionally count as signing a contract, we have no difficulty in seeing what is wrong with this argument. We all know what happens if someone writes his or her name under a contract just for fun or as a joke: if the procedure was correct (this may include that the person signing must be of a sound mind, fully conscious, etc), the joker still counts as having signed the contract and thereby as having undertaken the contractual commitments. It doesn't help the joker that he only wanted to make a joke. If the relevant people have a sense of humour, they might let the joker off the hook, but that doesn't detract from the fact that the joker does count as having signed. What about frauds? There could be several kinds of fraud. One kind only pretends to be going through the correct contract-signing procedure, but in fact he or she does not. This kind of fraud represents no counterexample, as the correct procedure was never carried out. Another kind of fraud carries out the correct procedure, but has no intentions of complying with the obligations he or she thereby creates. If this second fraud is good at being a fraud, he or she will manage to escape the sanctions for noncompliance. This type of fraud is not a counterexample either, because while the correct procedure was carried out, this did constitute the act of signing the contract with all the normative implications. Finally, let's consider actors: I believe actors on stage do not usually go through the correct procedure when the fictional characters they represent are signing contracts. Let's suppose that they really do write their character's name under a contractual document. This would still not be the correct procedure, because no-one signed their own name. But if we suppose that the actor is signing a contract in his or her own name, then (again if the procedure was correct) he or she may well count as having signed the contract.

With this in mind, let us think again about Davidson's jokers, storytellers and actors who utter assertoric sentences. Begin with the joker: Davidson seems to think that a joker can utter an assertoric sentence, and his utterance will not count as an assertion because it was intended as a joke. But life isn't quite as easy for a joker. Imagine a very clumsy joker, who utters the words "fuck off", addressing a dangerous-looking bouncer outside a night club. A moment later, he says: "only kidding". Has this joker, or hasn't he, told the bouncer to $\mathrm{f}^{* * *}$ off? I believe the only credible thing to say is that he has. Having meant 
it as a joke doesn't prevent it from being an insult and from creating the normative conversational facts that insulting someone brings about. The bouncer may have a sense of humour and let him off the hook, but that doesn't mean that the joker never insulted him.

Here is another example, more favourable to Davidson's idea of a joker: A and B, who are work colleagues, are conversing during their lunch break in a café near their workplace. Their boss, C, is mentioned. C is notoriously stingy and obsessed with his employees getting back on time from their lunch breaks. A utters: "You know, C has decided to hand out lunch-packs from now on and to force us to have lunch in the office. The cost will be deducted from our salaries.". The joke will work particularly well if B takes it seriously for a moment. But should we say that A's utterance was not an assertion that $\mathrm{C}$ has decided to hand out lunch packs etc? I believe that would be counterintuitive. Now, Davidson might insist that it is not an assertion, because it is a joke. But how do we explain that the joke works particularly well if B initially takes it seriously? I believe the best explanation is that A's utterance was an assertion (at least a C-assertion), and that as a result of a pragmatic process, it does not, ultimately count as a vicious attempt to deceive $\mathrm{B}$, but as a prank or joke.

There are other cases that might be described as joke-assertions where it is not essential that the audience take the utterance seriously. Thus, for example, B may answer A in the above example by saying: "Yeah, and he is going to chain us to the desk and hire a slave-driver with a big whip.". Cases like these should probably be treated as instances of story-telling.

But what should the adherent of conventional assertion say about story-telling? Several accounts are possible. On one view, conventional force-indicators involve a number of normality conditions. Thus, the procedure conventionally sufficient for asserting that $p$ does not only consist in uttering a sentence assertoric of $p$ to an audience, but the utterance must also be made as part of a serious conversation, i.e. not in the course of telling a story or developing some other fiction. On this view, the story-teller's utterances do indeed fail to be $\mathrm{C}$-assertions, but they also fail to be instances of the procedure performance of which is claimed to be sufficient for C-assertion. Thus storytellers aren't counterexamples to the view. ${ }^{21}$

If this is the best solution then the case of stage-assertion, while it doesn't prove the impossibility of force indicators, does constrain the sort of features that can count as force-indicators. It would show that moods are like indexical referring expressions: they need contextual completion to do their job of indicating force. This would not show that forces cannot be conventionally encoded-indexical reference is also conventionally encoded (the meaning of "you" together with the context of utterance conventionally determines the reference of utterances of "you").

But another view of story-telling is available. On that view, the story-teller's, novelist's, or narrator's utterances in the fictional context do count as C-assertions, but there are extra-linguistic rules that suspend or modify the usual normative consequences of making $\mathrm{C}$-assertions in the context of telling the story. Even though, in my experience,

\footnotetext{
${ }^{21}$ Dummett's seems to go down this route in his 1973. García-Carpintero endorses a similar account of moods in his 2004.
} 
it is very difficult to pursuade anyone of this view, it is in my view superior and highlights a further advantage of employing the notion of $\mathrm{C}$-assertion. So let me illustrate the view a little.

When narrators (e.g. novelists) make utterances, they use the full range of utterance types that are also used in non-fictional discourse. In particular, they will use assertoric, interrogative and imperative sentences. Apart from some stylistic differences, there are no surface differences between fictional and non-fictional discourse. Moreover, linguistic context has the same role in fiction and non-fiction: the fact that a dagger has been mentioned in previous discourse can make that dagger salient, so that it becomes the referent of an indexical or of an anaphoric pronoun. Ambiguous expressions can be disambiguated using linguistic context both in fiction and in non-fiction. Even more significantly, the difference between literal and non-literal meaning appears to apply to fiction just as it applies to non-fiction: a novelist can use irony, metaphor and implicatures and can convey information by using an interrogative sentence. Similarly, presupposition phenomena in fiction are no different from presupposition phenomena in non-fiction. The novelist can convey that the hero has a sister either by presupposing it or by using an assertoric sentence whose content is that the hero has a sister. Thus, there is a prima facie case that linguistically fictional and non-fictional discourse are uniform.

Some notions of C-assertion (but not all: consider Williamson's notion) can help us exploit the uniformity between fiction and non-fiction to the full. Consider a $\mathrm{C}$-account that views the normative role of $\mathrm{C}$-assertion, $\mathrm{C}$-question etc in terms of its effect on conversational score. It will treat the use of assertoric sentences in fiction as cases of $\mathrm{C}$ assertion, the use in fiction of sentences that require a presupposition as C-presupposing, the use of interrogative questions in fiction as $\mathrm{C}$-questions etc. Purely linguistic conversational rules are exactly the same in fiction and non-fiction. What is different in fiction is nothing linguistic. Rather the difference lies in the different non-linguistic aims we pursue in making fictional utterances. In fiction as in non-fiction it is inappropriate to presuppose something uncontroversial, to use an anaphor without antecedent, to use ungrammatical sentences etc. But in fiction it is usually ok to describe events and people that never existed, while this is not ok in most non-fictional contexts. On some people's view this means that we don't assert in fiction. In my view this shows that the norms that prohibit describing events and people that never existed cannot be purely linguistic norms, and in particular they cannot be norms of assertion.

As I have explained above, the controversial account of fictional assertion just outlined is not the only possible response to Davidson's challenge from storytelling. Thus, acceptance of this account is not essential to the overall aim of the paper. Readers not prepared to grant that story-tellers make genuine assertions are therefore invited to join those who defend the first of the views outlined.

The most complex of Davidson's three purported counterexamples is that of stageassertion. A special difficulty here is that the actors preforming the utterances are not themselves the originators of the phrases they utter. Rather, they are following a script. Clearly, we cannot treat the actors' utterances on stage as C-assertions that are subject to the rules of conversation. It would be absurd to say that the actor has violated a linguistic rule when he uttered a sentence that presupposed something not already in the conversation's background. If anyone has violated that rule, then it is the character 
portrayed by the actor. The actor himself is only subject to the norms of proper acting. Thus, actors on stage are most plausibly treated as not fulfilling the basic conditition of being part of a conversation. That's why they do not count as having C-asserted: while they do utter assertoric sentences, they do not count as participants in a conversation. In other words, they do not perform the procedure conventionally sufficient for $\mathrm{C}$-asserting. However, performance on stage can and should be treated as a representation of a conversation. The conversation represented does involve $\mathrm{C}$-assertions, inappropriate presuppositions etc.

The second of the above-described accounts of story-telling can say even more about stage-performances. In some sense, a theatre-performance is a special case of fiction; a special case of telling a story. However, the way in which the story is told is more elaborate. When in a novel the author writes "And then Smith said: 'You have betrayed me."', then a stage-representation of the same story will consist in the actor playing Smith uttering, at the right moment during the play, "You have betrayed me.". Thus the actors aren't the ones who are telling the story, or at least they are not doing it alone. Rather, the playwright, in collaboration with the crew of actors, director, stagesetters, etc, is C-asserting that such-and-such people acted and spoke in such and such a way.

I conclude that neither joking, nor story-telling nor stage-acting constitutes a counterexample to the thesis that there are conventional indicators of assertoric force.

\section{Non-sentential Assertion?}

The sorts of C-accounts of assertion I have outlined in section 3 involve the claim that there are force indicators that conventionally indicate assertion. $\mathrm{C}$-accounts are therefore committed to the view that some type of procedure is sufficient for C-assertion. Some Ctheorists might wish to claim in addition that the procedure in question is necessary for $\mathrm{C}$-assertion. However, there is a prima facie case against this view, at least if the procedure is to include utterance of an assertoric sentence. For there appear to be assertions that are effected by uttering strings that do not constitute sentences, let alone assertoric sentences. If, for example, I utter "Not yet." when my ping pong partner is signalling that she is about to serve and asking "Ready?", I am arguably thereby asserting that I am not yet ready (just as she has asked whether I am ready). I have not, however, uttered an assertoric sentence. Thus uttering an assertoric sentence cannot be necessary for asserting something.

The obvious move to make here, if one wants to defend the thesis that utterance of an assertoric sentence is necessary, is to claim that the utterance of the mere fragment "not yet" was elliptical for a full assertoric sentence. This move, however, faces a number of difficulties, pointed out in a series of papers by Stainton (e.g. 1995, 1997, 1998, forthcoming a, forthcoming b). One of the main difficulties is that (so it is claimed) ellipsis cannot occur in a position that is "linguistically discourse initial" coupled with the (apparent) fact that one can effect an assertion with a non-sentence even in such a position. This particular difficulty has been ably addressed by by Stanley 2000 and especially Merchant 2004. I have nothing to add to this (but see Stainton forthcoming a and $b$ for his responses). However, in one article (Stainton 1997), Stainton uses a different argument to show that apparently non-sentential utterances cannot be analysed 
as elliptical. In this article, he also argues that such utterances show Dummett's conventional view of assertion to be wrong. To my knowledge, this argument has not been answered. So in this section I shall try to provide an answer.

Stainton's argument is directed against conventional force-indicators of the stronger kind, i.e. force indicators that are not only sufficient but also necessary for assertion. The precise thesis he attacks (and tentatively ascribes to Dummett 1973) is the thesis (RS):

(RS) Convention Based Analysis of Assertion: A speaker S asserts that P iff: a. $\mathrm{S}$ utters an assertoric sentence whose sense is $\mathrm{P}$

b. The set $\mathrm{C}$ of conventionally specified conditions for assertion obtain. (Stainton 1997, p. 59)

Stainton argues that uttering an assertoric sentence cannot be necessary for assertion because assertions can be effected without uttering a sentence, namely by uttering nonsentential phrases or words that are not sentences, such as:

Very fast. (said as a boat is speeding by)

As I have already said, a natural move for the C-theorist would be to claim that (8) is an elliptical utterance. For example, (8) might be elliptical for

(8e) That boat is going very fast.

However, according to Stainton (1997), this move is not open to the C-theorist because if (8) were elliptical for (8e), then the audience should be able to respond by uttering

(9) That car is too. (in response to (8)).

He maintains that utterance (9) would be ungrammatical, and that this suggests that (8) was not elliptical in the proposed way after all. ${ }^{22}$

I want to show that Stainton's case provides no evidence for his conclusion. But it takes a little effort to unravel the knot he has tied. To begin with, I have some doubts about the claim that utterance (9) would be ungrammatical. However, let's accept for the sake of argument that it is (I shall come back to this). Accepting that (9) is ungrammatical does not yet amount to a concession that (8) is not elliptical. At most it amounts to a concession that (8) is not elliptical for (8e). (8) might be elliptical for a different sentence, one which does not license the response (9). Suppose, for example, that (8) is elliptical for

(8ee) That boat can go very fast.

In that case we would expect (9) to be ungrammatical, for a partial VP deletion, such as (9), does need to employ an auxiliary verb that matches with the antecedent. Thus the (supposed) ungrammaticality of (9) would be consistent with, and explained by, (8) being elliptical for the assertoric sentence (8ee).

\footnotetext{
${ }^{22}$ Stainton bases this conclusion on the following claim about grammar: "Across human languages, VP Deletion ... is grammatically possible only if a licensing sentential syntactic structure is present in prior discourse." (1997a, p. 65, my emphasis). Presumably he also assumes that the presence of a licensing sentential syntactic structure in prior discourse is sufficient for the grammaticality of verb deletion, for otherwise the argument would not even get off the ground.
} 
However, there are reasons to believe that (8) is not elliptical for (8ee) either, because if it was, then the response "That one can too" ought to be perfectly felicitous. However, it sounds odd, at the very least.

What can we make of this? Let's re-consider what is wrong with (9). I believe there is a straightforward explanation why (9) at least sounds a little odd. Consider the following two exchanges, each with three possible responses:

(A1) John: That dress looks very elegant.

(R1a) Mary: This skirt does too.

(R1b) Mary: *This skirt is too.

(R1c) Mary: This skirt too.

(A2) John: That dress is very elegant.

(R2a) Mary: *This skirt does too.

(R2b) Mary: This skirt is too

(R2c) Mary: This skirt too.

(R1b) and (R2a) are ungrammatical, because in each case the auxiliary does not match the antecedent. The other two responses are possible (even though the c-version is the most economical). Now consider another exchange, this time with an elliptical opening:

(A3) Very elegant. (said by John addressing Mary parading a dress she is trying on)

(R3a) This skirt does too. (said by Mary a minute later, now sporting a skirt)

(R3b) This skirt is too. (said by Mary a minute later, now sporting a skirt)

(R3c) This skirt too. (said by Mary a minute later, now sporting a skirt)

I believe that (R3a) and (R3b) are a little odd, but probably not ungrammatical. (R3c), however, is perfectly natural. The obvious explanation is that since (A3) is elliptical, there is some indeterminacy, or at least uncertainty, about the correct completion of (A3). However, only (R3c) is sufficiently neutral to fit with most plausible completions. ${ }^{23}$ That's why (R3a) and (R3b), while probably not ungrammatical, sound odd. Each of them would commit Mary to an unecessary level of specificity in her interpretation of (A3).

Now we can explain Stainton's case. There is a perfectly natural response to (8) which involves VP deletion, and this is "That car too.". This response is itself elliptical in an indeterminate way, to match the indeterminacy in the ellipsis that occurs in (8). Other responses are odd (even though not quite ungrammatical) because they are too specific about the correct completion of (8):

(8) Very fast. (said as a boat is speeding by)

(Ra) That car does too

( $\mathrm{Rb})$ That car is too.

(Rc) That car too.

\footnotetext{
${ }^{23}$ Why not all?-One plausible completion would be: "In that dress you look very elegant.". Neither of the three responses would be grammatical as a response to that antecedent. We need something like "In this skirt I do too.".
} 
I believe that this view is more plausible than Stainton's view that (9), i.e. (Rb), is ungrammatical. However, as I said above, even if it was ungrammatical, that wouldn't show that (8) is not elliptical for an assertoric sentence because it might be elliptical for a sentence to which (9) is an ungrammatical response.

Let's briefly take stock: I have shown that Stainton has provided no evidence that (8) is not elliptical. I now want to consider whether his example provides evidence that (8) $i$ is elliptical for an assertoric sentence, i.e. whether his example can be turned against its author. Stainton uses the following grammatical principle:

Across human languages, VP Deletion-leaving a verb phrase unpronounced-is grammatically possible only if a licensing sentential syntactic structure is present in prior discourse." (1997a, p. 65)

Now, (Rc) above quite clearly is grammatically possible as a response to (8). (Rc) seems to involve VP deletion. If so, then (8) must be sentential, that's what Stainton's principle tells us.

The problem with this argument is that it relies on the assumption that (Rc) involves VP deletion. Stainton will (correctly) complain that this assumption begs the question against him, for in his view (8) is genuinely non-sentential. So this argument is inconclusive. (However, his own objection to the C-account, in the form of (RS), has been refuted.)

There is also a different way to resist alleged counterexamples that involve nonsentential assertion, one that does not depend on the success of the ellipsis account. Elliptical sentences involve "unpronounced" syntactic elements. Now suppose that (8) and (A3) and similar examples are indeed elliptical for complete assertoric sentences. Then the question arises whether the mood, or other syntactic force indicator, of these sentences is included in the "unpronounced" part of the sentence, or whether it is already explicitly there. In the cases here discussed, mood is arguably explicit. The utterance (8) involves an inflection (intonation) typical of assertion, and this is marked (in my own and in Stainton's examples) with a full stop. An utterance of the same phrase in the same situation with an interrogative inflection (raising voice towards the end) would be elliptical for a complete interrogative sentence. However, if the force-element is not unpronounced, then a C-theorist could take the view that whether or not the utterances in question are utterances of sentences, they are utterances of assertoric (interrogative, etc.) types. This line of resistence to the nonsentential assertion objection does, however, require a change in Stainton's target analysis (RS): while (RS) makes utterance of an assertoric sentence necessary for assertion, a modified account requires merely utterance of a type involvig an assertoric force indicator. On this view, even non-sentences can exhibit force indicators.

\section{References}

Alston, William 2000: Illocutionary Acts and Sentence-Meaning, Ithaka, NY: Cornell University Press.

Austin, J. L. 1962: How To Do Things with Words, Oxford: Clarendon Press.

Bach, Kent 2001: "You Don’t Say". Synthese 128, pp. 15-44. 
Barker, Stephen 2004: Renewing Meaning: A Speech-Act Theoretic Approach, Oxford: Oxford University Press.

Bird, Graham 1994: "Relevance Theory and Speech Acts", in S. Tsohatzidis (ed.), Foundations of Speech Act Theory, London: Routledge, pp. 292-311.

Brandom, Robert 1983: “Assertion”. Nous 17, pp. 637-50.

Broome, John 1999: "Normative Requirements”. Ratio 12, pp. 398-419.

Davidson, Donald 1979: "Moods and performances", in A Margalit (ed), Meaning and Use, Dordrecht: Reidel. Reprinted in Davidson, Inquiries into Truth and Interpretation, pp. 109-21, Clarendon Press, Oxford, 1984.

Davidson Donald 1982: "Communication and Convention", in Davidson, Inquiries into Truth and Interpretation, pp. 265-80, Oxford: Clarendon Press 1984.

Davidson, Donald 1986: "A Nice Derangement of Epitaphs", in E. Lepore (ed.), Truth and Interpretation, Oxford: Blackwell, pp. 433-46.

Dummett, Michael 1973: Frege: Philosophy of Language. London: Duckworth.

Dummett, Michael 1993: "Mood, Force, and Convention", in B. Vermazen and M Hintikka (eds.), Essays on Davidson, Oxford: Oxford University Press. Reprinted in The Seas of Language, Oxford: Oxford University Press 1992.

García-Carpintero, Manuel 2001: "Gricean Reconstructions and the Semantics/Pragmatics Distinction”. Synthese 128, pp. 93-131.

García-Carpintero, Manuel 2004: "Assertion and the Semantics of Force-Markers", in Claudia Bianchi (ed.), The Semantics/Pragmatics Distinction, Stanford: CSLI Publications, pp. 133-66.

Harnish, Robert, M. 1994: "Mood, Meaning and Speech Acts", in S. Tsohatzidis (ed.), Foundations of Speech Act Theory, London: Routledge, pp. 407-59.

Hawthorne, John 1990: "A note on 'Languages and Language"”. Australasian Journal of Philosophy 68, pp. 116-118.

Hawthorne, John 1993: "Meaning and Evidence: A reply to Lewis", Australasian Journal of Philosophy 71, pp. 206-211.

Kölbel, Max 1998: “Lewis, Language, Lust and Lies”, Inquiry 41, pp. 301-15.

Laurence, Stephen 1996: “A Chomskian Alternative to Convention-Based Semantics". Mind 105, pp. 269-301.

Lewis, David 1975: "Languages and Language", in K. Gunderson (ed.), Minnesota Studies in the Philosophy of Science 7, University of Minnesota Press, pp. 3-35. Reprinted in Lewis 1983. Page references to reprinted version.

Lewis, David 1979: "Scorekeeping in a Language Game", Journal of Philosophical Logic 8, pp. 339-359. Reprinted in Lewis 1983. Page references to reprinted version.

Lewis, David 1983: Philosophical Papers, Oxford: Oxford University Press. 
Lewis, David 1992: "Meaning Without Use: Reply to Hawthorne", Australasian Journal of Philosophy 70, pp.106-110.

Merchant, Jason 2004: "Fragments and Ellipsis". Linguistics and Philosophy 27, pp. 661-738.

Millar, Alan 2004: Understanding People: Normativity and Rationalizing Explanation, Oxford: Oxford University Press.

Pagin, Peter forthcoming: “Is Assertion Social?". Journal of Pragmatics.

Predelli, Stefano 2005: Contexts, Oxford: Oxford University Press.

Recanati, François 2004: Literal Meaning, Cambridge: Cambridge University Press.

Rumfitt, Ian 1995: "Truth Conditions and Communication", Mind 104, pp. 827-62.

Sadock, Jerrold M. and and Zwicky, Arnold 1985: "Speech Act Distinctions in Syntax", in T. Shopen (ed.), Language Typology and Syntactic Description. Volume 1: Clause Structure, Cambridge: Cambridge University Press, pp. 155-96.

Segal, Gabriel 1990: "In the Mood for a Semantic Theory". Proceedings of the Aristotelian Society 41, pp. 103-18.

Searle, John 1969: Speech Acts. Cambridge: Cambridge University Press.

Sperber, Dan, and Wilson, Deirdre 1995: Relevance: Communication and Cognition (2nd edition), Oxford: Blackwell.

Stainton, Robert 1995: "Non-sentential Assertions and Semantic Ellipsis". Linguistics and Philosophy 18, pp. 281-296.

Stainton, Robert 1997: "What Assertion is not”. Philosophical Studies 85, pp. 57-73.

Stainton, Robert 1998: “Quantifier Phrases, Meaningfulness 'In Isolation', and Ellipsis”, Linguistics and Philosophy 21, pp. 311-340.

Stainton, Robert forthcoming a: "Neither Fragments nor Ellipsis", in L. Progovac et al. (eds.), The Syntax of Nonsententials, Philadelphia: John Benjamins.

Stainton, Robert forthcoming b: Words and Thoughts.

Stalnaker, Robert 2002: “Common Ground”. Linguistics and Philosophy 25, pp. 701-21.

Stanley, Jason 2000: “Context and Logical Form”. Linguistics and Philosophy 23: pp. $391-434$.

Stanley, Jason 2002: "Making it Articulated". Mind and Language 17, pp. 149-68.

Strawson, Peter F. 1964: "Intention and Convention in Speech Acts". Philosophical Review 73, pp. 439-60. Reprinted in J. R. Searle (ed.), Philosophy of Language, Oxford: Oxford University Press 1971.

Williamson, Timothy 1996: "Knowing and Asserting". Philosophical Review 105, pp. 489-523. This article reappears in revised form as chapter 11 of Williamson 2000.

Williamson, Timothy 2000: Knowledge and its Limits, Oxford: Oxford University Press. 
Wilson, Deirdre and Sperber, Dan 2002: “Truthfulness and Relevance". Mind 111, pp. 583-632. 